\title{
EMPRESAS COOPERATIVAS EN LA ACTIVIDAD TURÍSTICA SUSTENTABLE EN MÉXICO
}

\section{COOPERATIVE COMPANIES IN SUSTAINABLE TOURIST IN MEXICO}

\author{
Minerva C. Maldonado - Alcudia ${ }^{1}$ \\ César M. Maldonado - Alcudia. ${ }^{2}$ \\ ${ }^{1}$ Universidad Autónoma de Querétaro, México. correo: mm_alcudia@yahoo.com.mx \\ ${ }^{2}$ Universidad Autónoma de Querétaro, México. correo: c.maldonadoalcudia@ hotmail.com
}

\begin{tabular}{|l|l|}
\hline Recibido: 11.12 .17 & Aprobado: 07.09.18 \\
\hline
\end{tabular}

DOI:10.15517/isucr.v20i41.38780

\section{Resumen}

El presente capítulo los autores discernimos sobre la intricada relación en la que se desenvuelven las empresas cooperativas mexicanas, en el ámbito del turismo de naturaleza, en sus modalidades: ecoturismo, rural y de aventura. Entre las principales dificultades a las que se enfrentan, se puede mencionar el contexto y modelo económico en el cual se desenvuelven, (sistema que privilegia el libre mercado, la competencia, y el sostén a la empresa privada). Si bien es cierto que hay políticas y leyes que disponen apoyo al cooperativismo, estas empresas se han considerado como formas de asistencia a las comunidades rurales y grupos vulnerables. Dicha situación les permite participar dentro de esta modalidad para obtener fondos para realizar sus emprendimientos, sin embargo, se ha detectado que debido a la falta de experiencia de los socios; tanto en el cooperativismo, la gestión de la empresa y el establecimiento de relaciones con otros sectores; muchas de ellas colapsan ante las circunstancias y dinámicas de la sociedad. El objetivo del trabajo aquí plasmado es teorizar precisamente, cómo se entrelazan los factores del sistema social, turístico, económico para favorecer el desarrollo turístico sustentable a la luz del enfoque sistémico.

Palabras clave: Ecoturismo; Empresas; Cooperativas; México;

\begin{abstract}
:
The authors discern about the intricate relationship in which Mexican cooperative companies operate, in the field of nature tourism, in its modalities: ecotourism, rural and adventure. Among the main difficulties they face, we can mention the context and economic model in which they operate, (a system that privileges the free market, competition, and support for private companies).
\end{abstract}

Keyword: Ecoturism; Cooperatives; Companies; México; 


\section{Introducción}

La complejidad de la realidad del turismo como fenómeno social de desplazamiento voluntario y temporal de las personas, hacia los lugares elegidos como destinos turísticos a efectos de su recreación u ocio, se relaciona directamente con factores del entorno, que provocan efectos positivos o negativos en la actividad. Ellos repercuten directamente en la afluencia e ingresos, de manera que si hay alteraciones de acontecimientos en el orden social económico, político, cultural y ambiental, inmediatamente, hay una reacción en el mercado turístico y en general, en todas las otras actividades.

A efectos de explicar la dinámica, se hace uso de la teoría de sistemas que permite describir y explicar cómo estos factores se relacionan unos a otros y de qué manera se conjugan en los diferentes países para crear una oferta turística. Así mismo, se utiliza el enfoque de la economía solidaria para explicar cómo las cooperativas son una de las formas de empresas sociales que aportan al desarrollo sustentable.

Las características de la economía solidaria permiten elaborar propuestas de apoyo para las comunidades con vocación turística, de manera que sean las personas de la localidad quienes se vean directamente beneficiadas con el aprovechamiento sustentable de los recursos de la zona. El turismo sustentable se convierte en una oportunidad u estrategia para desarrollar la economía solidaria, el comercio justo y el cooperativismo. Esta propuesta permite generar ingresos, sin ánimo de lucro, para quienes menos oportunidades tienen, en un mundo donde la competencia turística se encuentra en manos de las grandes cadenas de hospedaje, alimento y producción de bienes de consumo en general, es decir, pertenecen a las grandes empresas tradicionales.

El turismo sustentable o sostenible de acuerdo a la Conferencia Mundial del Turismo Sostenible (CMTS, 1995: 1), "debe ser soportable ecológicamente a largo plazo, viable económicamente y equitativo desde una perspectiva ética y social para las comunidades locales". En este sentido resalta la obligación del turismo de contribuir al desarrollo sostenible a través del respeto del ambiente natural y cultural. Es importante resaltar, que esto se logra con la participación activa, comprometida de todos los actores de la sociedad sea destinos egresivos o receptivos. En los principios 7 y 8 de la Carta del turismo sostenible (CMTS, 1995: 2) se plantea:

7. Para participar en el desarrollo sostenible, el turismo debe asentarse sobre la diversidad de oportunidades ofrecidas por la economía local, garantizando su plena integración y contribuyendo positivamente al desarrollo económico local.

8. Toda opción de desarrollo turístico debe repercutir de forma efectiva en la mejora de la calidad de vida de la población e incidir en el enriquecimiento sociocultural de cada destino.

Llevar a cabo estos principios implica un cambio de actitud del turista: un modelo de consumo turístico, otros métodos de fijación de precios que este en relación al trabajo y los costos ambientales, elaboración de políticas medioambientales y observancia del cumplimiento de las mismas además del trabajo solidario, responsable y centrado en valores. La oferta que se crea para satisfacer a una nueva demanda de personas con visión y compromiso con el ambiente fue el turismo de naturaleza o alternativo, principalmente en dos modalidades ecoturismo y turismo rural. Ambas formas tienen bajo impacto medioambiental. La tercera forma de este modelo no es muy compatible con la 
sustentabilidad por el alto impacto que genera en los sitios donde se practica y es llamado turismo de aventura.

El turismo de naturaleza, sustentable o alternativo es definido por la Secretaria de Turismo como los viajes que tienen como fin realizar actividades recreativas en contacto directo con la naturaleza y las expresiones culturales que le envuelven con una actitud y compromiso de conocer, respetar, disfrutar y participar en la conservación de los recursos naturales y culturales.

\section{Desarrollo}

El turismo sustentable se debe contextualizar en un marco global, a fin de conocer las tendencias que generaron los dos grandes modelos turísticos que rigen la actividad turística mundial. La selección de la teoría de los sistemas, no sólo permite describir que es un sistema y los elementos que lo conforman, sino que además explica la dinámica de la interrelación de subsistemas y del sistema en general con otros en un ambiente en constante cambio. Ante la incertidumbre que se pueda generar, los sistemas buscan mecanismos de respuesta para tratar de sobrevivir a los impactos que se suceden en el macro sistema o macro ambiente, con la finalidad de descubrir nuevas oportunidades para competir.

El concepto de sistemas obligadamente remite a la Teoría General de Sistemas (TGS) creada por Ludwig Von Bertalanffy en la década de 1950 y publicada en 1968, quien para conceptualizar los fenómenos que la reducción mecanicista de la ciencia clásica no podía explicar, proporciona un marco teórico unificador, tanto para las ciencias naturales, como para las sociales, que necesitaban emplear conceptos tales como "organización", "totalidad", globalidad e "interacción dinámica". Lo lineal es sustituido por lo circular, ninguno de los cuales era fácil de estudiar por los métodos analíticos de las ciencias puras.

Uno de los aportes más importantes de la teoría sistémica formulada por Bertalanffy, es la concepción del sistema/entorno. La formación de los sistemas no depende de una estructura dada, sino que se logra a través de la interacción con el entorno como un factor constituyente. El problema que se plantea es la fijación de los límites entre sistema y entorno. El sistema, para poder ser sistema, debe diferenciarse o independizarse del entorno, pero a la vez debe mantener una dependencia del entorno, si quiere sobrevivir y evolucionar. El entorno es a la vez, fuente de perturbaciones y desequilibrios y fuente inagotable de recursos que posibilitan la supervivencia y el cambio del sistema (Velilla, 2002).

Todos los sistemas están orientados hacia un objetivo, lo cual es reconocido en la TGS como una constante lucha para mantener al sistema vivo ya sea éste, orgánico o social. En algunas ocasiones se pierde el equilibrio causando disfunciones al sistema, que pueden llevarlo al colapso y dejar de existir. Hay tres premisas básicas que caracterizan a los sistemas:

1. Los sistemas existen dentro de sistemas: cada sistema existe dentro de otro más grande.

2. Los sistemas son abiertos: es consecuencia del anterior. Cada sistema recibe y descarga en otro sistema.

3. Las funciones de un sistema dependen de su estructura.

Referido a la actividad turística y aplicando las premisas anteriores, se observa que el turismo está inmerso en el contexto general del sistema económico que rige al país, opera como sistema de producción de servicios con la misma mecánica de la ley de la demanda y oferta; situación que hace que su forma de organización se desenvuelva fundamentalmente en propiedad privada y empresas tradicionales. 
Otros autores como O’Connor (1997), Ackoff (1960), Rapport (1960), Sassure (1931) definen al sistema, como un conjunto organizado de elementos solidarios en interrelación mutua. Ladriére (1973) enfatiza en la indivisibilidad del sistema al explicar que la primera y fundamental complejidad del mismo es asociar en sí la idea de unidad, por una parte y la de diversidad o multiplicidad por la otra, que en principio se repelen y excluyen.

La complejidad de los sistemas está dada por las propiedades del conjunto. Bertanlaffy (1968) explica que esto se debe a que el todo es más que la suma de las partes. El sistema posee algo más que sus componentes considerados de forma aislada o yuxtapuesta:

- Su organización,

- La unidad global misma (el todo)

- Las cualidades y propiedades nuevas que emergen de la organización global.

Las cualidades nacen de las asociaciones y de las combinaciones. Esto hace emerger la estabilidad, cualidad indispensable para la vida. En el caso del sistema turístico está conformado por una base o infraestructura, la estructura y la superestructura turística, la comunidad anfitriona, los atractivos, la demanda, los productos y servicios, además de la oferta complementaria.

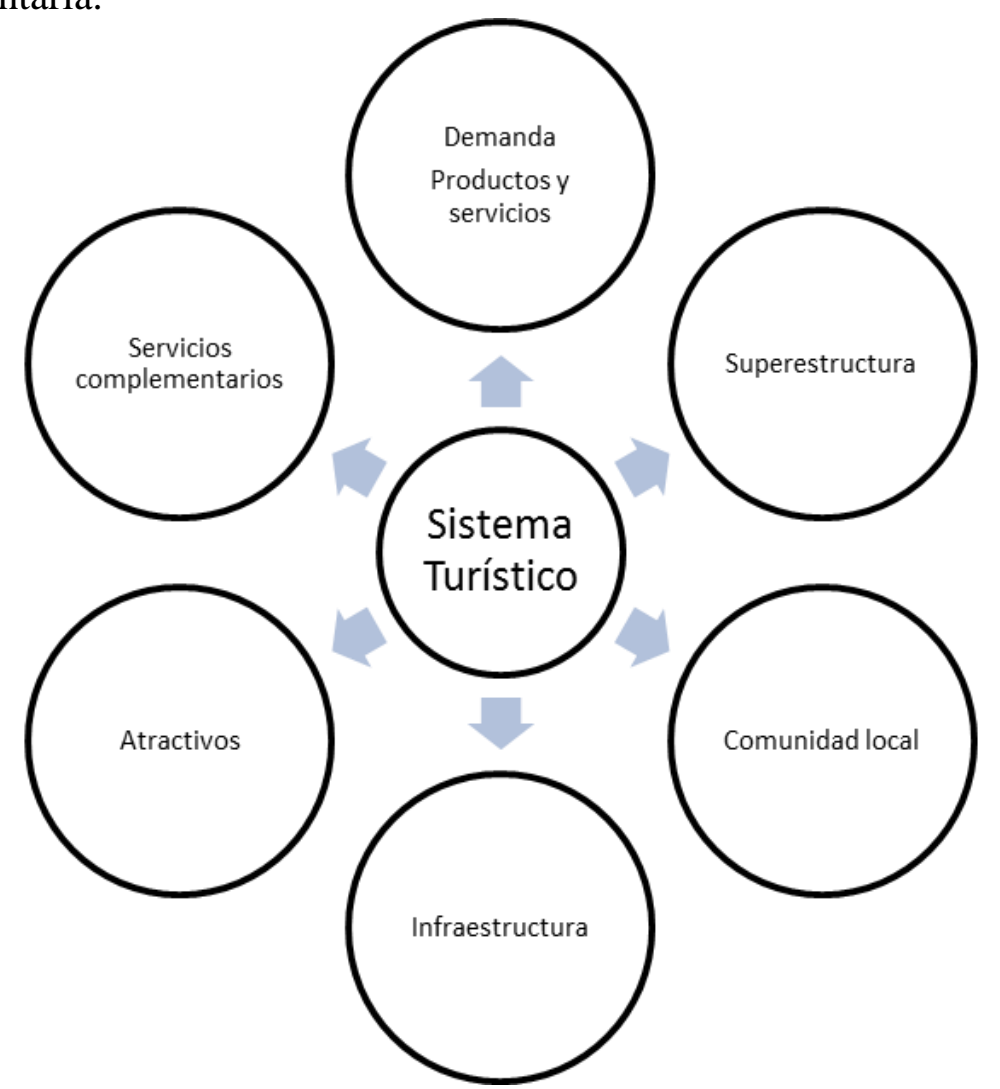

Figura 1 :Sistema turístico. Fuente: Elaboración autores.

La comunidad anfitriona como un subsistema a su vez refleja claramente el principio holográmico de los sistemas complejos y pone en evidencia la aparente paradoja de las organizaciones complejas, donde no sólo la parte se encuentra en el todo, sino el todo está inscrito en la parte (patrimonio genético). Es decir, como sistema social refleja desde el punto económico las actividades a las cuales se dedica la comunidad, su cultura, el sistema político, las leyes y normas que la rigen tanto formal como informalmente. En éste sentido, su propia 
auto organización propicia que se cumpla también el principio dialógico en donde se da el orden-desorden-organización.

Las contradicciones en las zonas turísticas están a la orden del día: se cuenta con una infraestructura adecuada en ellas, mientras que los residentes en ellas carecen de las básicas. Lo mismo se puede mencionar con respecto a la estructura, se venden los espacios naturales de recreación y los habitantes de las zonas poco a poco, son desplazados por la inversión inmobiliaria ya sea para hoteles, restaurantes y bares, casinos, discotecas, marinas, etc. En cuanto a la superestructura conformada por organismos gubernamentales y no gubernamentales cuya función es coordinar y regular la actividad turística se da un constante choque de intereses. Esta situación es natural porque los sistemas no operan en un equilibrio duradero como observa Morin (1997). El fenómeno de la complejidad, genera antagonismo de complementariedad: toda relación organizacional y por lo tanto todo sistema, comporta y produce el antagonismo, al mismo tiempo, que la complementariedad. Por ejemplo, la inversión en infraestructura en las playas va dirigida a proyectos de diversificación y genera el enriquecimiento de la oferta. También se ha optado en invertir en la mejora de las playas, dotando a este espacio de elementos que hagan que su disfrute le resulte al turista más satisfactorio por ejemplo: limpieza y accesorios, vigilancia, servicios sanitarios e higiénicos, paseos marítimos, parques o zonas lúdicas en playa, colectores de basura, regaderas o duchas, etc. La inversión en las instalaciones y equipamiento (estructura) involucra mejoras en los jardines, creación de parques urbanos, mobiliario, puntos limpios, señalización.

Los atractivos naturales y culturales, patrimonio de las comunidades, se ven afectados ante la demanda por la saturación de los espacios en la relación hombre-entorno. Es importante que el turista asuma el principio de "la reintroducción del conocedor en todo conocimiento". Es decir, que el hombre asuma la responsabilidad compartida del disfrute, cuidado y conservación de su entorno natural y cultural, en busca de la restauración del medio. El ser humano es el elemento dinamizador de la actividad turística; quien busca para su descanso los destinos, conforme a sus patrones de vida, valores, hábitos de consumo. Indican cuáles son las motivaciones y las expectativas que favorecen el desplazamiento. Esta información de retroalimentación es recogida en el sistema turístico para responder con nuevos productos y/o servicios.

\section{Características de los Modelos Turísticos}

El turismo a partir de la segunda guerra mundial se desarrolló de manera rápida, gracias a: los avances en los sistemas de comunicación, los medios de transporte, la disponibilidad de los trabajadores de mayor tiempo libre en función de jornadas laborales de 40 horas, las facilidades en viajes por paquetes; esto hizo que el turismo se volviera una práctica de masas. Durante esta época surge el Modelo de la Industria Turística (MIT) es decir, un modelo cuya pretensión es generar el mayor crecimiento en las comunidades receptoras, con el único fin de obtener el máximo beneficio económico. Su objetivo es la rentabilidad; dicho Modelo (Molina, 1987) finca sus bases en seis propósitos específicos, localizables rápidamente, en el concepto sol y playa.

Al revisar la promoción turística de un destino vía internet, revista o folleteria podemos observar los principios del modelo industrial o tradicional los cuales son: concentración, maximización, unificación, especialización, sincronización y centralización. Así también por observación directa, se pueden identificar dichos principios. Las imágenes que nos venden evocan una gran concentración de hoteles, discotecas, bares, restaurantes, son zonas donde 
se agrupan los bienes y servicios turísticos en un espacio geográfico. Por lo general, los destinos y las empresas tienen la tendencia a la maximización del espacio físico para obtener mayor rentabilidad. Existe una tendencia al crecimiento, mayor número de cuartos, más restaurante, considerando que entre más grande son mejores.

La forma en la que se practica el turismo está relacionada con las imágenes que capturamos en los medios masivos de comunicación; se aprenden a "divertir" conforme a los roles y patrones establecidos. Es como la moda: se vende un estereotipo de mujer u hombre, en vestidos y zapatos y el consumidor adopta temporalmente. En el caso del turismo, ese estereotipo del turista en la playa, se ha mantenido y seguirá, pero de igual manera hay otras formas que surgen para dar satisfacción a la diversidad.

Muchos de esos productos y servicios están unificados o estandarizados en cadenas de hospedaje, alimentación, transporte, el trato del personal, su apariencia, los colores de los establecimientos, la preparación, la presentación de alimentos, etc. La sincronización, es vital para efectuar un producto estandarizado, ya que se requiere establecer tiempos de producción, tanto de servicios, como de productos. A esta regulación de tiempos se le llama sincronización.

Cada persona que encontramos dentro de un establecimiento de hospedaje o alimentación, forma parte de una división del trabajo. Esto hace que los individuos desarrollen una tarea concreta, en el menor tiempo posible; la especialización trae como consecuencia el abaratamiento de la mano de obra.

En esa pirámide son los ejecutivos o la alta gerencia, quienes toman las decisiones, sin tomar en cuenta las opiniones, y recomendaciones de aquellos que tienen el trato directo con el turista (centralización).

El Modelo de Industria Turística es promovido básicamente por los empresarios quienes ven al turista en el papel de consumidor- espectador. Se les ha creado la necesidad de consumir para satisfacer su status y su sentido de pertenencia. De esta manera, los productos y servicios se diseñan pensando primero en el producto, luego en el servicio y por último en la experiencia. Así también a los prestadores de servicios como meros engranajes de la maquinaria turística.

La oferta primordial del turismo industrial es el conocido como Sol y Playa. Los destinos tradicionales son Acapulco, Mazatlán, Manzanillo, Puerto Vallarta y los Centros Integralmente Planeados son Cancún, Los Cabos, Ixtapa, Loreto, Huatulco, entre otros; ejemplos todos ellos, de la depredación, la contaminación ambiental y la saturación de la comunidad.

Esta es una visión mecanicista que trae como consecuencias el uso irracional, tanto del recurso humano, como de los recursos naturales y culturales de las localidades receptoras. Algunos países empezaron a registrar disminución en el número de visitantes, a causa de los descuidos ambientales y por los modelos urbanos carentes de la infraestructura, instalaciones y equipamiento.

\section{Modelo de Turismo de naturaleza, sustentable o alternativo.}

Es a partir de la toma de conciencia del individuo sobre la importancia de preservar el medio ambiente natural, (a raíz de los problemas de contaminación, del exterminio de flora y fauna, del estudio de los fenómenos desde un punto de vista integrador, de los cambios en el mercado mundial, y la globalización) que aparecen grupos opositores a este modelo industrial 
desordenado y depredador, en muchos casos, promovidos directamente por partidos políticos.

A la luz de estos hechos, un segmento del mercado del turismo cambió de actitudes y se lanzó a buscar nuevas formas de practicar el turismo, en lugares donde no había grandes concentraciones de personas, tratando de causar el menor impacto en el ambiente. Las decisiones del turista cambiaron, nació un nuevo turista, capaz de decidir qué tipo de experiencia desea realizar un turista ambientalista.

El turismo moderno retoma esta visión y marca una estrategia mediadora basada en la sustentabilidad. Según la World Commission on Environment and Development, organismo dependiente de la ONU, el Desarrollo Sustentable significa el encontrar la forma de satisfacer las necesidades actuales, sin comprometer la habilidad de las futuras generaciones, para encontrar la satisfacción de las propias.

La forma operativa del concepto de la sustentabilidad recae en nueve principios rectores, en los cuales se señala: el compromiso de respetar y cuidar a la comunidad de seres vivientes, mejorar la calidad de vida humana: conservar la diversidad de la tierra, tratando de reducir al mínimo el agotamiento de los recursos renovables y no renovables; mantenerse dentro de la capacidad de carga de la tierra. También se señala que es necesario un cambio de actitud y de prácticas personales; considera la necesidad de facultar a las comunidades para que cuiden de su propio medio ambiente, y proporcionar un marco nacional y mundial para la integración del desarrollo y la conservación a través de alianzas mundiales.

Los objetivos del modelo sustentable del turismo son: la autogestión, auto-respeto y autodesarrollo, siendo su finalidad primordial brindar experiencia. También se busca ofrecer al turista mayor participación en la creación de su experiencia.

Actualmente de acuerdo con la Organización Mundial del Turismo (OMT), el segmento de más acelerado crecimiento es el turismo "alternativo". La Secretaria de Turismo define el Turismo Alternativo como aquellos viajes que tienen como fin el realizar actividades recreativas en contacto directo con la naturaleza y las expresiones culturales que le envuelven; con una actitud y compromiso de conocer, respetar, disfrutar y participar en la conservación de los recursos naturales y culturales. Incluye todas aquellas actividades conocidas como de turismo especializado: turismo de aventura, ecoturismo y rural.

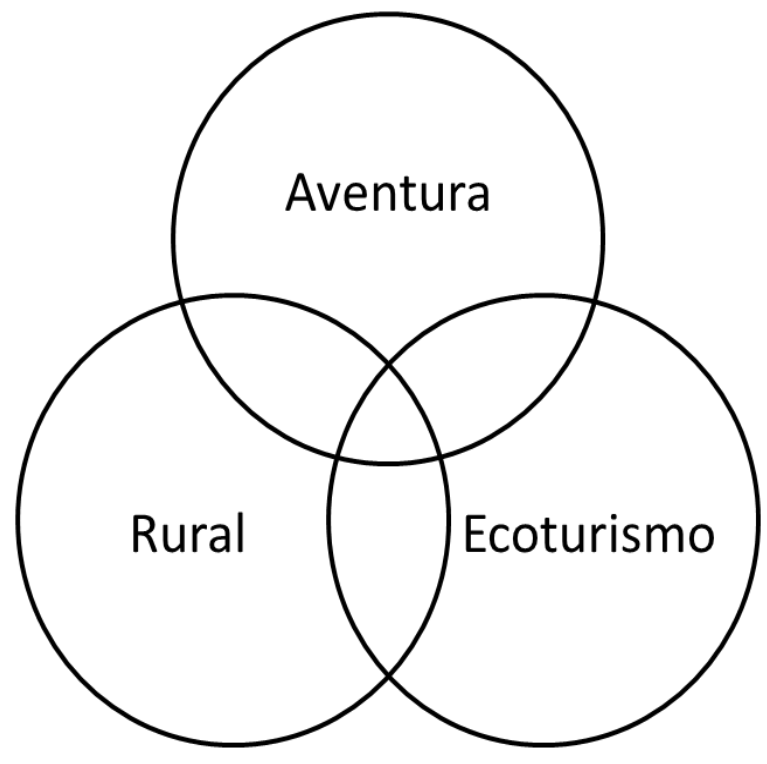


Figura 2: Modalidades del turismo alternativo y su impacto ambiental y cultural. Turismo de Aventura: son viajes de actividades recreativas en contacto con la naturaleza participando en actividades extremas; pueden ser en el aire, por tierra, por agua. En su conjunto se destacan 22 actividades (paracaidismo, vuelo en globo, descenso de montañas, caminatas, bicicleta de montaña, descenso en río, buceo, entre otros.) Esta modalidad es de al impacto en la naturaleza.

Ecoturismo: turismo centrado en la contemplación y disfrute de la naturaleza, se distinguen 12 actividades para la práctica del ecoturismo (observación de flora y fauna, geológica, sideral, de fotografía, etc.)

Turismo Rural: paseos en donde se busca interactuar con las personas y el ambiente rural, con 9 actividades para su práctica (etnoturismo, vivencias místicas, artesanales, medicina tradicional y gastronomía, entre otras).

La tipología del turista varía, ya que sus motivaciones y expectativas, así como las maneras de satisfacerlas son diferentes y van acorde con sus características de personalidad y estilos de vida. De acuerdo con San Martín (2004; Plog, 1977) sus características psicográficas tienden a agrupar en la generalidad, a los turistas del modelo industrial en los psicocéntricos. Los turistas alternos estarían en su clasificación alocéntricos, (aun cuando se pueda criticar que no hay un perfil puro), sus categorías intermedias son medio céntricos, cuasi psicocéntricos y los cuasi alocéntricos tratan de salvar éste problema de clasificación.

El Turismo sustentable ofrece una oportunidad para la economía solidaria, el desarrollo del comercio justo y el cooperativismo. Esta propuesta permite generar ingresos sin ánimo de lucro para quienes menos oportunidades tienen, en un mundo donde la competencia turística entre destinos se encuentra en manos de las grandes cadenas de transportes, hospedaje, alimento y producción de bienes de consumo en general. Será necesario además que exista correspondencia con los principios de sustentabilidad social, cultural y natural.

La economía solidaria fundamentada teóricamente en los procesos que realiza el ser humano para producir y distribuir riqueza, implica que éste genere desde el punto de vista ético un beneficio colectivo.

Economía solidaria es un conjunto de fuerzas sociales, identificadas por ideales solidarios y humanistas, que la habiliten para gestionar talento humano, recursos naturales, científicos, tecnológicos y financieros $\mathrm{y}$, como resultado de esa gestión, para generar procesos de desarrollo integral y sostenible para el género humano en general y para cada comunidad o agrupación familiares particular. En su conjunto, constituye un eje dinamizador de procesos sociales, culturales y políticos, para la construcción de una nueva civilización, capaz de construir la felicidad humana (Moreno, 2001:11).

Moreno enfatiza que en la economía solidaria, el desarrollo se mide por el cambio cualitativo que se logre en la potencialización de las cualidades humanas y el grado de bienestar social. "Se puede lograr mediante el uso racional de la naturaleza y la construcción de una red, denominada Factor C, en la cual todos los miembros del colectivo empresarial, local, regional y nacional, interactúan para el logro de los objetivos comunes" Moreno (2001:13). El autor citado propone que para lograr tales efectos, el modelo de desarrollo solidario debe atender el perfeccionamiento del proceso de producción, distribución, consumo y acumulación, así como la diversificación, expansión e integración de la capacidad productiva, a fin de construir una economía más perfecta, con vistas al futuro y en interrelación con los demás procesos y factores.

Das Ros (2007; Lara y Urbiola, 2009) mencionan que esta propuesta de desarrollo no es excluyente en los sectores más vulnerables y es propicia para estimular la capacidad creativa 
e innovadora de los individuos, organizados en actividades económicos-sociales. Algunas de las características que conforman la economía solidaria son enlistadas en la obra de Lara y Urbiola describen que la misma, retoma y destaca situaciones del orden cultural que deben ser rescatadas para la sana convivencia. Por ejemplo el sentido de la pertenencia a un grupo social determinado que es lo que le da identidad al individuo; los valores éticos y el sentido de trabajo, basado, en el compromiso, la equidad y la cooperación. Las posibilidades de la economía solidaria permiten elaborar estrategias colectivas de sobrevivencia, creación de empresas comunitarias, participativas de gestión asociada y autónoma todo en aras de un bien común.

Una economía solidaria utiliza diferentes formas organizacionales como son las cooperativas, las mutuales, las asociaciones, los organismos no gubernamentales entre otras formas. En cuanto a los productos y servicios que ofrecen en el mercado del turismo alternativo utilizan el tipo cooperativa que favorece a los pequeños productores o prestadores de servicios unidos, para brindar un producto de mayor calidad y mejor precio.

El cooperativismo, de acuerdo con Pineda (1999), constituye una organización fundada en la solidaridad y desarrollada en un sistema democrático, con ánimo del no lucro. Tiene su eje central en el ser humano y procura satisfacer las necesidades, en un marco de equidad y solidaridad, situación que no sucede con las empresas del sistema capitalista, cuyo centro motivador es el capital y la ganancia.

La organización de las cooperativas permite al asociado sentirse y realizarse en un marco jurídico de igualdad, ya que su decisión vale por igual, independientemente del capital aportado. Tiene administración democrática que implica autonomía, su propiedad es colectiva y la distribución de los beneficios se capitaliza o distribuyen de acuerdo a lo establecido en los estatutos de la entidad (Lambert, 1965; Pineda, 1999).

El Cooperativismo en México, se define de acuerdo con la Ley General de Sociedades Cooperativas como "una forma de asociación social integrada por personas físicas con base en intereses comunes y en los principios de solidaridad, esfuerzo propio y ayuda mutua, con el propósito de satisfacer necesidades individuales y colectivas, a través de la realización de actividades económicas de producción, distribución y consumo de bienes y servicios" (LGSC, 2009).

La empresa cooperativa ha sido considerada una forma de asociación para obtener un bienestar común a partir de elaborar, producir u otorgar servicios. En este caso particular, trata el turismo con un enfoque de sustentabilidad.

A lo largo de este documento se ha dejado en claro la importancia de la sustentabilidad se requiere de una sustentabilidad. El cooperativismo puede precisamente aportar en este sentido, sin embargo, se requiere de una formación y acompañamiento adecuado, de manera tal que las comunidades integradas al sistema cooperativista operen en forma coordinada.

El cooperativismo en el área del turismo de naturaleza, sustentable o alternativo se presenta en:

- Las actividades Ecoturísticas: existen cooperativas dedicadas a los paseos o tours "verdes", la educación ambiental, la observación sideral, de aves, protección de la flora y fauna. Un ejemplo del trabajo ecoturístico desde hace cinco años se da en Quintana Roo donde hay grupos indígenas mayas con cooperativas Ecoturísticas en Sian Ka'an.

- Las actividades de Aventura: pesca recreativa, montañismo, senderismo, caminata, ciclismo entre otras. Algunos ejemplos son las cooperativas de paseos turísticos en balsas, lanchas y barcos; en Islas Mujeres, Holbox e Islas Contoy en Quintana Roo; 
cooperativas para la observación de aves como en los casos de Zapotalillo, Zapotal, Cerro hermoso en el estado de Oaxaca (Moreno y Cruz, 2007); cooperativas de educación de la vida sostenible como Las Cañadas, Huatusco, Veracruz.

- Servicios de Hospedaje: donde las personas de la comunidad se unen para brindar el servicio de alojamiento, creando cabañas, casas rurales, hoteles ecoturístico buscando emplear recursos gubernamentales para tal fin; como en el caso de escudo jaguar centro ecoturístico, operado por indígenas Choles de Ocosingo y el centro ecoturístico las Guacamayas, operado por el grupo indígena Chinanteco, (ambos en el estado de Chiapas).

- Otros servicios: de Alimentos y Bebidas, de transporte, producción de artesanía, representaciones culturales, entre otras.

\section{Discusión}

En el proceso de obtención de información sobre un inventario de actividades turísticas alternativas nacional, se encontró que de los 31 estados de la República y el Distrito Federal el segmento de turismo de naturaleza, alternativo o sustentable con más oferta turística es el de ecoturismo. A este le sigue el de aventura, y, el menos ofertado es el turismo rural. Los estados que ofertan los tres tipos son Chiapas, Chihuahua, Veracruz, Oaxaca y el Distrito Federal; en cambio el que menos oferta presenta, es el estado de Sinaloa.

Las actividades de turismo rural tienen un gran potencial en nuestro país, sin embargo, son pocos los estados que están orientando y fortaleciendo este nicho. El turismo rural tiene entre sus bondades el rescate del patrimonio cultural de la localidad, la revaloración de las tradiciones locales y la vida cotidiana. Los Estados de Campeche, Chiapas, Chihuahua, DF, Guanajuato, Hidalgo, México, Michoacán, Nuevo León, Puebla, Querétaro, Quintana Roo, San Luis Potosí, Sonora, Tamaulipas, Veracruz, Yucatán, en su oferta de turismo rural, ofrecen etnoturismo, agroturismo, medicina tradicional, talleres gastronómicos, talleres artesanales, vivencias místicas, aprendizaje de dialectos.

La oferta de ecoturismo es la que tiene mayor creación de cooperativas turísticas, tanto en hospedaje, servicios de alimentación, transporte, actividades para la práctica del ecoturismo, elaboración de productos artesanales.

Se observa la falta de capacitación a los socios de las cooperativas turísticas a nivel nacional, en temas como gestión y educación cooperativa, administración, contabilidad y uso de tecnología (relacionados a los tipos y modalidades de turismo de naturaleza).

\section{Conclusiones}

El turismo alternativo en sus dos modalidades: rural y ecoturismo, favorece el desarrollo local, ya que se apega a las características de la economía solidaria, del comercio justo y posibilita la creación de los tres tipos de organizaciones solidarias.

Los grupos asociados deberán estudiar y capacitarse en la temática del turismo, procurar certificarse y no sólo tener reconocimientos, ya que como se mencionó anteriormente, son modalidades de alta especialización y algunas de alto riesgo.

Para que las empresas cooperativas puedan, efectivamente, participar en la actividad turística sustentable deberá aprender, incorporar, reglamentar y supervisar que tanto los socios, la comunidad, el gobierno, los turistas y los agentes operadores asuman la responsabilidad para la conservación del patrimonio natural y cultural. 
Los socios deberán participar en cursos, talleres y aprender a elaborar planes de manejo de loa recursos naturales y culturales de su región, para un mejor aprovechamiento.

Se debe apoyar a las personas de la localidad unan sus esfuerzos, conocimientos, experiencias para lograr beneficios en conjunto: algunos creando artesanías propias de la región, otros dedicados a la gastronomía; grupos diversos ofreciendo productos y servicios de calidad elaborados por ellos mismos, siempre acorde a los principios rectores de la sustentabilidad. Se debe procurar hacer cadenas productivas y de servicio turístico, de manera que no compitan y saturen el mercado, entre ellos mismos.

Por su naturaleza de producción, el turismo de naturaleza sustentable o alternativo no es masivo. Es un producto relativamente de costo alto porque precisa mantener un medio ambiente sano. Producir de manera artesanal hace que el producto o servicio eleve su precio; motivo por el cual los socios cooperativistas y la comunidad deben trabajar en conjunto para elevar el grado de satisfacción y experiencia del turista.

Se debe considerar diversificar las actividades productivas de las comunidades rurales, ya que el turismo es una actividad donde hay una estacionalidad muy marcada por respeto a la capacidad de carga de los suelos y los tiempos de recuperación de la naturaleza.

\section{Referencias bibliográficas}

Ackoff, Russell. (1974). Redesigning the future: A system approach to societal problems. New York: J. Wiley \& Sons.

Boullón Roberto y Diego Boullón. (2008). Turismo rural. México: Trillas.

Caracciolo Basco Mercedes y María del Pilar Foti Laxalde. (2003). Economía solidaria y capital social. Buenos Aires: Paídos.

Ladriére, J. (1973) Vie sociales et destinée. Gem-bloux: Duculot.

Lara Gómez, Graciela y Alejandra E. Urbiola Solis. (2009). Visión Global de las Cooperativas. México: Plaza y Valdéz.

Ley General de Sociedades Cooperativas. (2009). México: Diario Oficial de la Federación.

Molina, Sergio. (1987). El turismo fenómeno social. México: Trillas

Molina, Sergio. (2000). Turismo y Ecología. México: Trillas.

Moreno Avendaño, José del C. (2001). Economía Solidaria. Colombia: (s. e.)

Moreno Berriochoa, Dionisio V. y José Cruz Bojorques Baños. (2007). La observación de aves como actividad ecoturístico en la región costa de Oaxaca. Revista Ciencia y Mar XI. http://www.umar.mx/revistas/33/observacion-de-aves.pdf (consultado el julio 2010).

O'connor, J. y McDemont I. (1997). The Art of Systems Thinking: Essential Skills for Creativity and Problem Solving: San Francisco: Thorsins.

Pineda Suárez Carlos Julio. (1999). Las Empresas de la Economía solidaria en Iberoamerica. Colombia: MCGraw Hill.

San Martín, García Jesús Emiliano. (2004). Psicosociología del Ocio y el Turismo. España: Aljibe.

Secretaria de Turismo. (2007). Perfil de los Mercados turísticos emisores. Compendio 20062007. México: SECTUR

Velilla, Marco Antonio. (2002). Manual de iniciación pedagógica al pensamiento complejo. Colombia: Instituto Colombiano de Fomento a la EducaciónSuperior y UNESCO.

Wearing Stephen y John Neil. (1999). Ecoturismo. Madrid: Editorial Síntesis

Stiglitz Joseph E y Andrew Charlton. 2007. Comercio Justo para todos. Madrid: Taurus. 
InterSedes, $\mathbf{N}^{\circ}$ 41. Vol XX (2019). ISSN 2215-2458

Conferencia Mundial de Turismo Sostenible. (1995). Carta sobre el turismo sostenible. España. http://www.turismo-sostenible.org/docs/Carta-del-Turismo-Sostenible.pdf (consultado 30 julio 2013). 